\title{
How far did we get?
}

\author{
Fred T. Bosman
}

Received: 18 January 2013 / Accepted: 22 January 2013 /Published online: 2 February 2013

(C) Springer-Verlag Berlin Heidelberg 2013

The year 2012 was exciting for many reasons. A significant amount of progress was made on the strategic issues that I outlined last year. The 'niche' we defined for Virchows Archiv has been well received, and with this editorial policy, we have been able to maintain a reasonable copy flow, in terms of content mostly corresponding to that niche. How we will attain the set goals has become clearer. An essential element is the composition of the editorial team. You will have noticed on the opening page of the journal that the functions have been renamed: what used to be Managing Editor is now Associate Editor. The real Managing Editor Dagmar Schmöe, who served the journal for 9 years running the daily affairs from her Kiel office, retires. We owe many thanks to Dagmar for largely hidden but essential contributions to the journal. Her function will be taken over, at least for the time being, by an in-house Editorial Assistant in the Springer office. The terms of office of Vincenzo Eusebi and Günter Klöppel as Managing Editor and Reviews Editor have come to an end. I should like to thank them both for many years of dedicated service to the pathology community in general and Virchows Archiv in particular. Günter Klöppel served the journal for more than 20 years; during his term as Editor in Chief, he has been highly instrumental in getting the Virchows Archiv to the stature it has today and he made it the 'European Journal of Pathology', official journal of the European Society of Pathology. We will continue to profit from their experience, as they will migrate into the category of 'past editors', maintaining an advisory role for the journal. Daniela Massi started her term as Associate Editor and we wish her lots of pleasure and satisfaction in this function.

\section{F. T. Bosman $(\bowtie)$}

University Institute of Pathology, Lausanne University Hospital,

Rue du Bugnon 25,

1011 Lausanne, Switzerland

e-mail: fred.bosman@chuv.ch
An issue of continuous preoccupation is the quality of scientific writing and sometimes of the science. Many of the submitted papers fall short of the high standards we would like to maintain, even though they might get published with a significant amount of additional editorial work. Which issues are at stake?

1. Many papers do not start with a clearly conceived working hypothesis. Rather often, the justification for a reported study is 'the expression of molecule $\mathrm{X}$ has not been studied in tumor $\mathrm{Y}$ and so we performed immunohistochemistry to determine expression and assess associations with clinic-pathological parameters'. That is not enough. A working hypothesis should underpin the questions asked, the choice of the patient cohort under study and the chosen experimental design. In the review process, we will pay more attention to this and manuscripts might get rejected without review because of a lacking working hypothesis.

2. The lead author is insufficiently familiar with scientific writing in English. As many of our authors are nonnative English speakers, this is not surprising. Papers regularly are rejected because of poor writing, even though the scientific content of the paper might have been sufficient. To alleviate this problem, at least in part, I have tended to extensively edit many manuscripts, once they passed the peer review process and were considered as acceptable for publication. This is not a sustainable solution in the long run, and increasingly, papers go back to the authors with the request to have them edited by a native speaker or, often even better, by a scientific writer. In the future, more papers will be rejected before peer review in view of insufficient writing, with the possibility to resubmit after language editing of the manuscript. Frequently, the issues at stake in a particular manuscript are not limited to proper use of the English language. Authors might not 
have managed to write exactly what they wanted to say. Often, their intentions more or less transpire through the overall context of a phrase or a paragraph, but the text as written fails to clearly convey the message. This is where the help of a professional writer might come in handy. Good writing may be in part a natural gift but mostly it is a skill that we all need to and can master with adequate training.

3. Title and abstract insufficiently cover the content of the paper. The ideal title will obviously state what the paper is all about but equally important is the 'eye-catching' element: a good title should invite the reader to read at least the abstract and preferably the whole paper. Titles help to 'sell' a paper. The same holds true for an abstract, which should convey in a succinct and lucid way what is in the paper with sufficient factual information to convince the reader.

4. Biomarker studies concern only one marker and prognostic or predictive value is not assessed through multivariate analysis and/or application in a independent validation cohort. This is a very frequent problem, which will be more stringently dealt with in the future. We will more strictly enforce the REMARK criteria for biomarker studies, which constitute a very significant proportion of the papers we publish.

5. The technical quality of immunohistochemical studies is not always optimal. Important issues here are the speci- ficity of the applied antibody(ies), which is often taken for granted but - certainly in the case of new biomarkersneeds to be specifically tested. Then there is the reading of the results of immunohistochemical stains which not infrequently is inadequate, at least when the quality of the photomicrographs is taken as a measure. Quantitation or rather semi-quantitation is often substandard. Inappropriate use of semi-quantitative scoring approaches and haphazardly chosen cut-off points or over-fitting of data are frequent problems here.

Some ideas I ventured a year ago are just out of reach at this time. News and views require too much time. Pathology 100 years ago sounds nice but in reality turned out to be more a curiosity than illuminating. Key projects for improving the journal will be an active Review Paper programme, including an Annual Review Issue, which will be published regularly as of early 2014. Actively soliciting authors to submit their best papers to Virchows Archiv will be essential to get to the high quality copy flow we strive for. Together we will get there. Submit your best papers to your own journal. Let us know what you think of your journal. Let the journal continue to be a lively means of scientific communication.

Fred T. Bosman

Editor in Chief

Virchows Archiv 